\title{
Research Paper: Preparing the Background of the Organizational Forgetting and Its Role in Improving the Performance of Emergency Bases Through Human Capital
}

\author{
Mirza Hasan Hoseini ${ }^{1}$, Reza Norouzi Ajirloo $^{1^{*}}$ (D) Iman Azizi $^{2}$ \\ 1. Department of Management, Payame Noor University, Tehran, Iran. \\ 2. Young Researchers and Elite Club, Yasuj Branch, Islamic Azad University, Yasuj, Iran.
}

\begin{tabular}{|c|c|}
\hline $\begin{array}{l}\text { Use your device to scan } \\
\text { and read the article online }\end{array}$ & Chtat on: Hoseini MH, Norouzi Ajirloo R, Azizi I. Preparing the Background of the Organizational Forgetting and Its Role in Improv- \\
\hline 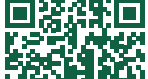 & $\begin{array}{l}\text { ing the Performance of Emergency Bases Through Human Capital. Health in Emergencies and Disasters Quarterly. 2019; 4(4):217-228. } \\
\text { http://dx.doi.org/10.32598/hdq.4.4.217 }\end{array}$ \\
\hline 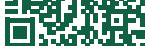 & dei : http://dx.doi.org/10.32598/hdq.4.4.217 \\
\hline
\end{tabular}

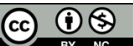

Article info:

Received: 10 Jan 2019

Accepted: 03 May 2019

Available Online: 01 Jul 2019

\section{Keywords:}

Human capital, Organizational forgetting, ,Performance, Shiraz emergency bases

\begin{abstract}
Background: Human capital development in emergency departments of the country has been very slow despite all the efforts of scholars and experts. This study was conducted to investigate the organizational forgetting context and its role in improving the performance of emergency departments of the country through human capital in Shiraz emergency bases.

Materials and Methods: This study has a correlational research design. We used the Aledo Ruíz et al. (2017) questionnaire to measure research variables. The statistical population comprised all personnel of the Shiraz emergency bases. The questionnaire was randomly distributed among the staff of Shiraz emergency bases and 136 questionnaires were selected for statistical analysis. To investigate the research hypotheses, we used structural equation analysis with the partial least squares method in SmartPLS software.
\end{abstract}

Results: The results of the data analysis indicated that the exogenous study variables of integration of concepts $(\beta=0.226, \mathrm{P}<0.05)$, coordination of insights $(\beta=0.12, \mathrm{P}<0.05)$, and changing personal habits $(\beta=0.42, \mathrm{P}<0.05)$ have a direct and positive effect on human capital. Also, human capital $(\beta=0.73, \mathrm{P}<0.05)$ was positively correlated with the performance of emergency bases.

Conclusion: Findings show that generating organizational forgetting has a positive relationship with human capital. If the employees can develop their skills by reflecting on their past, present, and future decisions or through a dialogue with their managers, they can change their behaviors and ideas and create new ones. So if managers encourage employees to transfer their knowledge to other coworkers and use their expertise to develop new ideas and solutions, they can develop human capital. The findings also indicate a positive relationship between human capital and organizational performance. Thus, if the emergency bases regard organizational forgetting as an early stage in the creation of human capital, they can improve organizational performance. Besides, the results showed that organizational forgetting has an indirect impact on organizational performance through the development and establishing of new capabilities and skills that increase the value of human capital.

\footnotetext{
* Corresponding Author:

Reza Norouzi Ajirloo, PhD.

Address: Department of Management, Payame Noor University, Tehran, Iran

E-mail: rezanorouzi20@yahoo.com
} 


\section{Introduction}

$\mathbf{T}$

he results of much of the research on the role and importance of human resources in the growth and development of organizations, and in some cases, on societies assert that without investing in human resources, communities cannot develop. Nowadays, researchers in the field of human resources have realized that human resources are an invaluable factor and capital for the growth and development of organizations and countries [1].

In the second half of this century, a significant part of the progress of developed countries has been due to the transformation of their skilled human resources. If labor, capital, and land were the main factors of production in the past, technology changes, human resources, and productivity improvements are realized as the growth factors today. The experiences of successful and leading organizations on the value of human resources demonstrate the importance of the human capital employed in those organizations [2]. Also, in the present period, the success of organizations depends mainly on their selfconfidence, efforts, motivation, and satisfaction with their human resources. In other words, the efficiency and effectiveness of organizations are directly related to the efficiency and effectiveness of their human resources.

To deliver desirable and appropriate behavior in line with the goals of the organization, the human resources must be both motivated and properly encouraged, and this goal cannot be achieved except by identifying behavioral causes, desires, as well as reasons for employees' motivation and satisfaction [3].

In a knowledge-based economy, the ability to create and use intangible assets will result in a fundamental competence for organizations [4]. Based on experience, enhancing employees' skills and capabilities have a direct impact on financial outcomes and, as a result, on the company's performance [5]. Therefore, the assessment and valuation of the firms' human capital are of great importance. However, in our country, the concept of human capital is quite new and managers are unfamiliar with it and often ignore its value. If the managers understand the importance and value of their human resources, they recognize them and trust them as the core assets of the organization and attempt to enhance their scientific and professional status. In this regard, they will be able to perform with confidence, and as a result, gain competitive advantage and reduce the internal and external pressures imposed on themselves and the organization [6].
Success in creating useful human capital depends on organizational forgetting, as acquiring new knowledge requires abandoning outdated values or behaviors $[7,8]$. For example, when promoted, members of the organization are asked to give up their technical skills, which were useful for previous positions but not in their higher positions. This concept states that one of the critical factors affecting the development and quality of an organization's human capital is the extent to which it updates its scientific structures [9].

The development of human capital means the knowledge, skills, and capabilities that exist individually or collectively in a company's human resources, directly affect performance outcomes [10]. In a study of large Spanish organizations, the researchers found that valuebased and unique employees (i.e., employees with firmspecific knowledge, skills, and abilities) had a positive relationship with the organization's productivity and competitiveness [11].

It has become increasingly common to address various aspects of human capital development and analyze the results of investment, planning, training of forces, and assessing future needs of human resources, especially in advanced countries. In this regard, the efforts of scholars and experts in this field guide managers of various organizations. Large service organizations, including emergency bases, though much later, contributed to this effort and began utilizing current human resource development systems. However, all issues such as substantial investment in cost-effective technology, general goals of emergencies in comprehensive health care services and equitable access of the community, improved health care and disease management, preparedness for medical emergencies in accidents and disasters, enormous share of human resources in emergency expenditures, and achievement of their organizational goals require the best possible use of human resources using modern scientific and practical methods.

The system of emergency management and medical emergencies is responsible for providing medical care to the patient in case of emergency and, if necessary transfer the patient to medical centers [12]. Employees are the most crucial resource of this system. Since a medical emergency is critical and influential on the health of other people, enabling them to play their part and have a sense of self-efficacy is one of the most critical factors enhancing the efficiency and performance of medical emergency personnel. 
There is a lack of optimal utilization of intangible assets and knowledge-based resources and capital in emergency bases. Improving the performance and productivity and replacing the waste of organizational knowledge by retirement or dismissal of employees, as well as unplanned efforts to prevent re-work and waste of intellectual and material capital, calls for organizational forgetting, which is a vital and fundamental element of human capital.

Emergency bases of the country are one of the infrastructures in the country that its assets are precious. The human resources of the emergency bases play a valuable role, as some of their errors and repetitions can be costly due to failure to record them in the organization's memory. One of the problems that the emergency bases had to deal with was the lost experiences of human resources. After gaining a lot of experience and training, the staff is being retired or left the organization for whatever reason and take away all their experiences. In other words, these precious experiences do not remain in the memory of the organization.

Therefore, despite little scientific attention on human resource development on emergency bases, it is the basis for removing old and inefficient knowledge and creating a new one to improve the performance of emergency bases. So far, no research has addressed this issue and its shortcomings. The present study seeks to determine the role of organizational forgetting in improving the performance of emergency bases through human capital.

\section{Theoretical grounds}

Before organizations learn new concepts, they must forget what is not useful for their organizations. Therefore, the knowledge management effort is based on two bases: first, the organization must be able to learn the new knowledge referred to in organizational learning management literature, and second, the organization must be capable of controlling its existing knowledge and, when necessary, modify it more or less, which is referred to as organizational forgetting [13].

Organizational forgetting as a new concept in the field of science has been the subject of the study of the researchers recently. In the first scientific stream, Smat and Morton and Smat have associated organizational forgetting with the concept of the devaluation of knowledge in production planning and large-scale planning. Wickand and Anderson developed the first measures at the operational level, based on knowledge degradation studies, and the interruption causes in the production process [14].

In the ground of organizational theories, researchers have proposed the concept of forgetting in the process of intentional or unintentional loss of organizational knowledge. Some other authors have also defined forgetting as a necessary process for converting dominant views of the organization into new ones: "Try new ideas before organizing." Organizations have to discover and destroy old ideas. Lack of knowledge from learning, inability to participate in coding and documenting knowledge, and lack of motivation to share knowledge are the most critical factors for knowledge forgetting in organizations [15].

Philips and de Holan believe that forgetting has the potential to add a new and vital dimension to our understanding of the dynamics of organizational knowledge, but this concept requires a specific and extensive research program. They discuss that forgetting (in the sense of forgetting old knowledge to create space for new knowledge) occurs before, during, and after learning processes. Forgetting also has an important impact on the effectiveness of learning processes in the organization [13]. Although anyone can forget differently, researchers have suggested that forgetting can be accomplished through three different processes:

1. Awareness is a process through which some people can be informed of outdated rules, procedures, or processes. This can be done by identifying one's own mistakes or errors; 2. Quitting allows people to avoid repeating old mistakes, especially when they happen unintentionally; 3 . Relearning involves the ability to learn new things. When a person is doing something new, he or she is in the process of forgetting and replacing new items with the old ones $[9,16]$.

Preparing a background for forgetting enables the organization to identify minor errors, mistakes, or facts that may need to be eliminated or ignored. For example, when managers learn from their mistakes and correct their decision-making patterns, they are ignoring their old or false patterns [17]. In this regard, the researchers argue that "replacing old knowledge can be necessary for organizations looking for new products or services that require new ideas and views" [18]. Thus, organizational forgetting helps to prepare the necessary working ground for acquiring and producing new knowledge. 


\section{Organizational forgetting and human capital}

The emergence of a new knowledge-based economy has increased the interest of researchers in the study of human capital, which is used as a tool to determine the value of the company [19].

The analysis of the human factor in the context of the capital is not a new issue. The analogy between man and his skills and physical capital has a long history [20]. Early attempts to argue for the concept of human capital had been made since the $17^{\text {th }}$ century, but a clear and unified theory on the subject was developed in the 1950s [21]. This concept, which is also used today in the run-up to the century of knowledge-based economies in the management and business science literature, well illustrates the importance of human resources in organizations [22]. Today, human capital is the most valuable asset of any country and organization, since human is recognized as central in the paradigm of sustainable development. Human resources are considered the goal of development and key to its continuation [23].

In order to identify incorrect knowledge and replace it with new or modified ones, an organizational forgetting context is needed $[24,25]$. This study considers that organizational forgetting requires three dimensions:

1. Checking insights coordination: This considers to end employees' habituated sense of comfort and raise awareness of new insights; 2. A framework for changing people's habits: This challenges the prohibition of bad habits and inappropriate values; as a result, a person, though not understanding the new idea, is persuaded to embrace the change; 3. A framework for integrating emerged concepts: This refers to the process of organization that can empower employees to employ talent by implementing new ways of thinking based on the use of new scientific structures.

According to Cepeda et al., organizations can enable people to coordinate patterns of their thoughts and the nature of shared interests with organizational forgetting to avoid the new workplace culture [26]. Employees can forget outdated knowledge and develop and learn up-to-date knowledge. They must, therefore, have the ability to forget about learning new things, which is a key to real learning found in reviewing and removing old habits and practices that are no longer appropriate for the company [27].

Based on these ideas, organizations should imply different strategies to eliminate obsolete knowledge and create new organizational knowledge through the ex- ploitation of employee's information. Scientific sources related to organizational learning state that this information is rooted in the individual [28]. As a result, organizational forgetting contributes to the preparation of the context for updating knowledge and scientific structures [29]. Thus, as employees learn knowledge and share it with other employees, human capital is created, and organizational learning emerges. In this regard, the following hypotheses can be put forward:

Hypothesis 1: The extent to which emergency bases achieve the integration of concepts emerging through organizational forgetting has a positive relationship with the extent to which human capital is created;

Hypothesis 2: The extent to which emergency bases achieve coordination insights through organizational forgetting has a positive relationship with the extent to which human capital is created;

Hypothesis 3: The extent to which emergency bases achieve changing personal habits in employees through organizational forgetting has a positive relationship with the extent to which human capital is created.

\section{Human capital and organizational performance}

The question now is whether human capital directly affects the performance of emergency bases. Conceptually, human capital encompasses any value-conscious learning that leads to the development of one's thoughts [30]. Many studies have identified human capital as a necessary and determinant of organizational performance and even global competitive advantage [31].

Experts and researchers believe that the main issue in all organizational analysis is the performance, and it is difficult to imagine an organization that is not subject to performance measurement. They regard the performance of the organization as an extension of the theory of the organization and consider it as a central issue in the operating mode [32]. Organizational performance is a complex phenomenon that is perhaps the simplest term for a set of activities aimed at achieving organizational goals. Thus, organizational performance is concerned with how much an organization has achieved its goals [33].

The measurable outcomes of organizational decisions and actions that indicate the extent of success and the achievements [34] and all other measured organizational successes reflected in sales, equity, profit, market value, and book value show the organizational performance [6]. The resourcebased view embedded in strategic management theory 
justifies the existence of such an advantage. Because the distinctive nature of the company's entire human resource stock, and not just senior managers, provides the basis for a unique approach, and thus the potential for superior performance or sustainable competitive advantage.

As Zhao et al. noted, the emergence of new knowledge leads to changes in knowledge structures through the creation of new habits that can help employees improve their skills and performance [35]. Therefore, managers should support new knowledge and encourage employees to share their knowledge with other employees. In this way, they contribute to both updating human capital and improve organizational performance [36]. So the following hypothesis can be put forward:

Hypothesis 4: The extent to which emergency bases develop human resources will have a positive relationship with the extent to which the performance of the emergency bases improves.

\section{Conceptual research model}

Since the purpose of this study is to investigate the role of organizational forgetting to improve the performance of emergency bases through human capital, the overall framework of this research is to explain the issue systematically. The conceptual model shown in Figure 1 is used to test the study hypotheses.

\section{Materials and Methods}

This research is a correlational study in terms of methodology and applied in terms of outcomes. Library resources, including documents, books, and scientific articles, have been used to formulate principles, definitions, and theoretical concepts. A standard questionnaire was used to collect the data needed to test the hypotheses.

The Aldo Royce et al. questionnaire was used to measure the research variables that consists of 42 standard questions: 6 questions related to "the integration of concepts emerged", 6 questions on "coordination of insights", 6 questions on "changing individual habits", 18 questions on "human capital", and 6 questions on "organizational performance" [37]. The questionnaire was presented to some experts in Human Resource Management and Organizational Behavior working in universities for examining its content validity. After making some corrections and approving by the experts, about 30 questionnaires were distributed among the statistical population to ensure its reliability and face-validity.

At first, the respondents could not understand some of the questions, but after repeatedly translating the text and eliminating some of the questions, the questionnaire was formally accepted, and the agreed questionnaire was used as a data collection tool. The statistical population includes all personnel of Shiraz emergency bases, which includes 18 bases along with a motor emergency base, communication and administrative unit, and 210 staff.

Cochran formula was used for calculating the sample size. A total of 160 questionnaires were randomly distributed among the personnel of the Shiraz emergency bases, which finally, 136 questionnaires were selected for statistical analysis. A variety of statistical indicators, including frequency, percentage, and various types of tables and graphs, were used to describe the collected data.

In the inferential statistics section, structural equation analysis and partial least squares were conducted

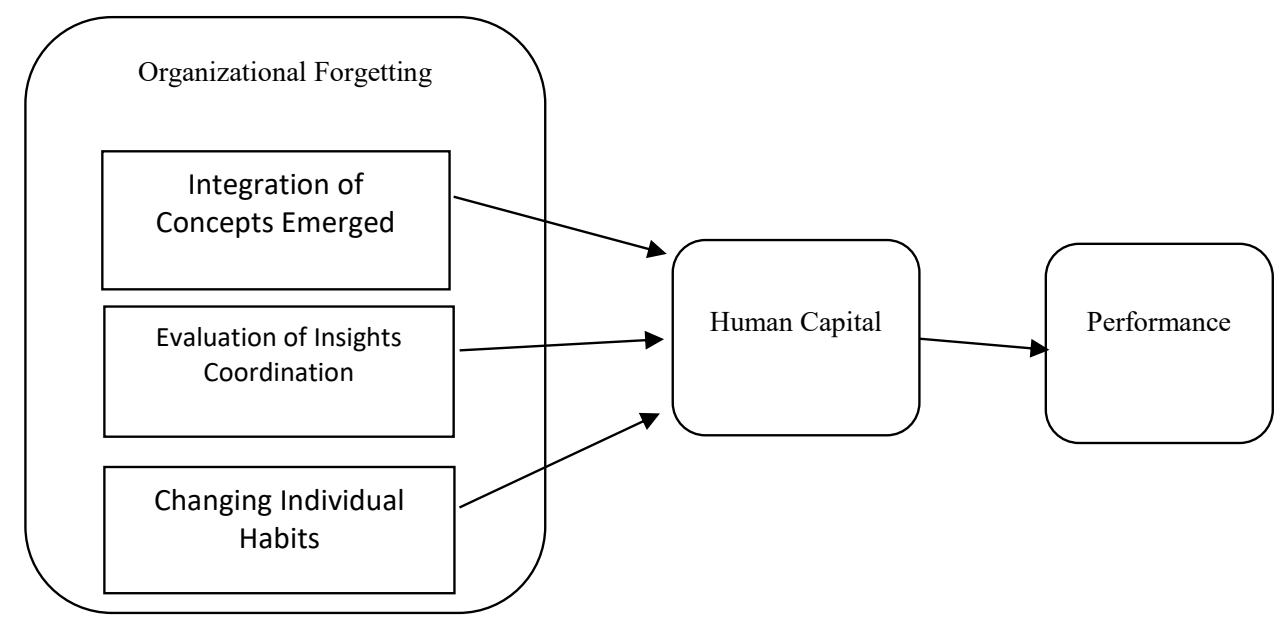

Figure 1. Conceptual Research Model [37] 
Table 1. Results of the AVE from the research constructs

\begin{tabular}{ccccccc}
\hline $\begin{array}{c}\text { Variable } \\
\text { Criteria }\end{array}$ & $\begin{array}{c}\text { Integration of } \\
\text { Concepts Emerged }\end{array}$ & $\begin{array}{c}\text { Coordinating } \\
\text { Insights }\end{array}$ & $\begin{array}{c}\text { Changing } \\
\text { Individual Habits }\end{array}$ & $\begin{array}{c}\text { Human } \\
\text { Capital }\end{array}$ & Function \\
\hline AVE & 0.764 & 0.816 & 0.519 & 0.642 & 0.799 \\
CR & 0.928 & 0.930 & 0.932 & 0.876 & 0.988 \\
\hline
\end{tabular}

Abbreviations: AVE; average variance extracted, CR; composite reliability.

Health in
Emergencies and |D] isasters [Oluarterly

Table 2. Comparison matrix of AVE (average variance extracted) root with constructs coefficient correlation (divergent validity)

\begin{tabular}{|c|c|c|c|c|c|}
\hline Variables & $\begin{array}{c}\text { Integration of } \\
\text { Concepts Emerged }\end{array}$ & $\begin{array}{l}\text { Coordinating } \\
\text { Insights }\end{array}$ & $\begin{array}{c}\text { Changing } \\
\text { Individual Habits }\end{array}$ & $\begin{array}{l}\text { Human } \\
\text { Capital }\end{array}$ & Function \\
\hline Integration of concepts emerged & 0.874 & & & & \\
\hline Coordinating insights & 0.425 & 0.904 & & & \\
\hline Changing individual habits & 0.541 & 0.614 & 0.720 & & \\
\hline Human capital & 0.456 & 0.512 & 0.326 & 0.801 & \\
\hline Function & 0.547 & 0.643 & 0.428 & 0.347 & 0.894 \\
\hline
\end{tabular}

in Smart-PLS software to investigate the research hypotheses. In the descriptive statistics section, standard statistical software such as Excel and SPSS were used.

\section{Results}

In this study, the structural equation modeling was applied with partial least squares (PLS) to test the hypothesis and model accuracy. PLS is a variance-based approach that requires fewer requirements than similar structural equation techniques such as LISREL and AMOS [38]. Its main advantage is its less sample size modeling compared with the LISREL [39]. It is also proposed as a powerful method in situations where the number of samples and measurement items is limited, and the distribution of variables can be uncertain.

PLS modeling is done in two stages: first, the measurement model is examined through validity and reliability analysis and confirmatory factor analysis. In the second step, the structural model is examined by estimating the path between the variables and determining the model fit indices.

\section{Step one: measurement model}

The test of the measurement model is related to the validity and reliability of measuring instruments.

\section{Validity}

For evaluation of convergent validity, the AVE (average variance extracted) and CR (composite reliability) criteria were used, the results of which are shown for the six variables of the research in Table 1 . The CR values higher than 0.7 and AVE values higher than 0.5 are two necessary conditions for convergent validity and correlation of the constructs. As shown in Table 2, all CR values were higher than 0.7 , and the values of AVE were higher than 0.5 , which confirms that the convergent validity of this questionnaire is acceptable.

\section{Reliability}

To check the reliability of the questionnaire, in addition to the Cronbach alpha coefficient presented in Table 3, which confirms the appropriate reliability of the questionnaire, the PLS method was used which uses index reliability. The reliability of the index is also calculated by measuring the factor loadings by calculating the correlation coefficients of the indices between its constructs. If this value is equal to or greater than 0.4 [30], the reliability of that measurement model is acceptable. But if the factor loadings between one question and the corresponding dimension is less than 0.4, that question can be excluded from subsequent modeling and analysis. 
Table 3. Cronbach alpha coefficient

\begin{tabular}{ccccc}
\hline Research Constructs & $\begin{array}{c}\text { Integration of } \\
\text { Concepts Emerged }\end{array}$ & $\begin{array}{c}\text { Coordinating } \\
\text { Insights }\end{array}$ & $\begin{array}{c}\text { Changing } \\
\text { Individual Habits }\end{array}$ & $\begin{array}{c}\text { Human } \\
\text { Capital }\end{array}$ \\
\hline Cronbach alpha coefficient & 0.897 & 0.888 & 0.922 & 0.749 \\
\hline
\end{tabular}

As shown in Figure 2, all values of factor loadings between constructs and questions are greater than 0.4 , indicating a high correlation.

\section{Step two: structural model and hypotheses testing}

A structural model test relates to testing research hypotheses and the effect of hidden variables on each other. Bootstrapping command of SmartPLS software was used to confirm the research hypotheses, which shows the resulting output of $t$ coefficients (Figure 3 ). When $t$ values are higher than +1.96 and less than -1.96 , it indicates the significance of the relevant parameter and subsequently confirms the research hypotheses.

\section{Methods for evaluating shaping measurement models}

One way to assess shaping models is the coefficient of determination (R2). It examines what percentage of the variance of a dependent variable is explained by the independent variable(s). Thus, it is normal that this value for the independent variable equals 0 and greater than 0 for the dependent variable. The higher this value, the higher the coefficient of influence of the independent variables on the dependent ones.
According to the coefficient of determination of the model, it can be said that the dimensions of organizational forgetting, including the integration of emerging concepts, the co-ordination of insights, and the change of personal habits, have been able to explain 0.514 of the variable variance of human capital. Human capital has also been able to explain 0.535 of the variance of organizational performance.

Researchers have identified three values of $0.19,0.33$, and 0.67 as the criterion values for weak, medium, and strong values in $\mathrm{R}^{2}$. So, the model has appropriate predictability, and the remaining amount is related to the prediction error and can include other factors affecting human capital and organizational performance.

\section{Response to research hypotheses}

According to the results of the path coefficient and the tstatistic, the extent of emergency bases access to "integration of concepts emerged", "evaluation of the coordination of insights", and "changing personal habits through organizational forgetting" has a positive relationship with the extent to which human capital is created. Besides, the extent the emergency bases develop human capital has a positive

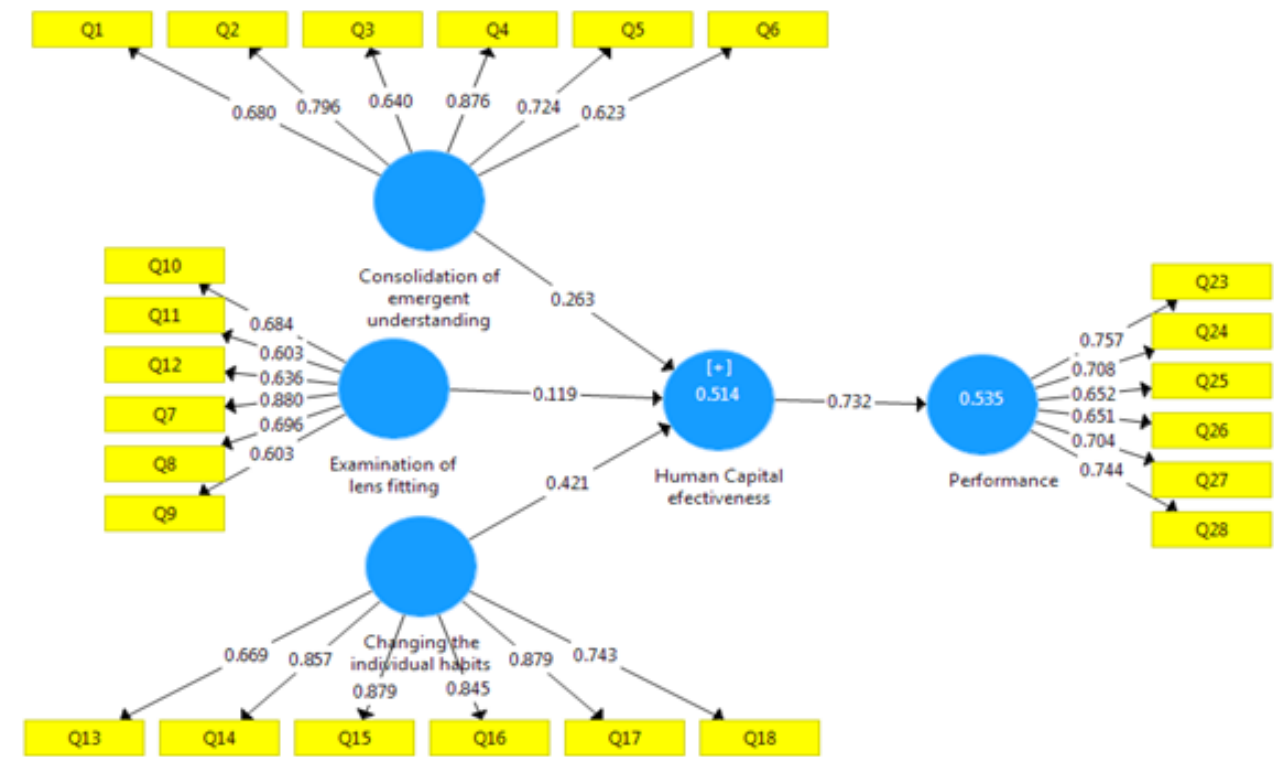

Figure 2. tested research model (path and factor loadings coefficients) 


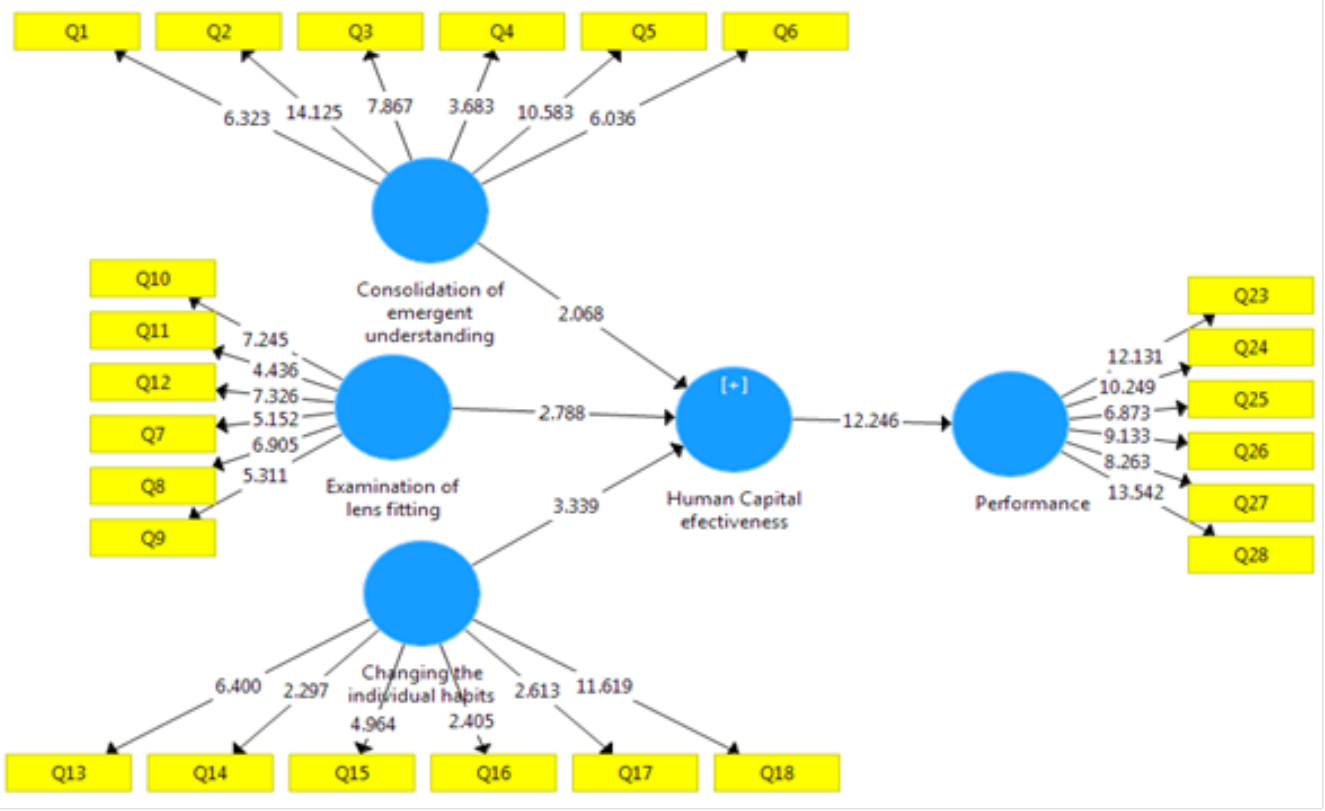

Figure 3. $t$ coefficients

Health in
Emergencies and |D]isasters [Oluarterly

relationship with the extent to which the performance of emergency bases improves (Figure 4).

\section{Discussion}

In this study, we designed a model to investigate variables related to organizational performance based on research background. In this structural model, we considered how organizational forgetting affects human capital and improves organizational performance. Find- ings show that creating organizational forgetting has a positive relationship with human capital. If employees can develop their skills through reflection on their past, present, and future decisions or conversations with their managers, they can change their behaviors and ideas and create new knowledge. The managers are expected to encourage employees to transfer their knowledge to other employees and use their expertise to develop new ideas and solutions and thus develop human capital.

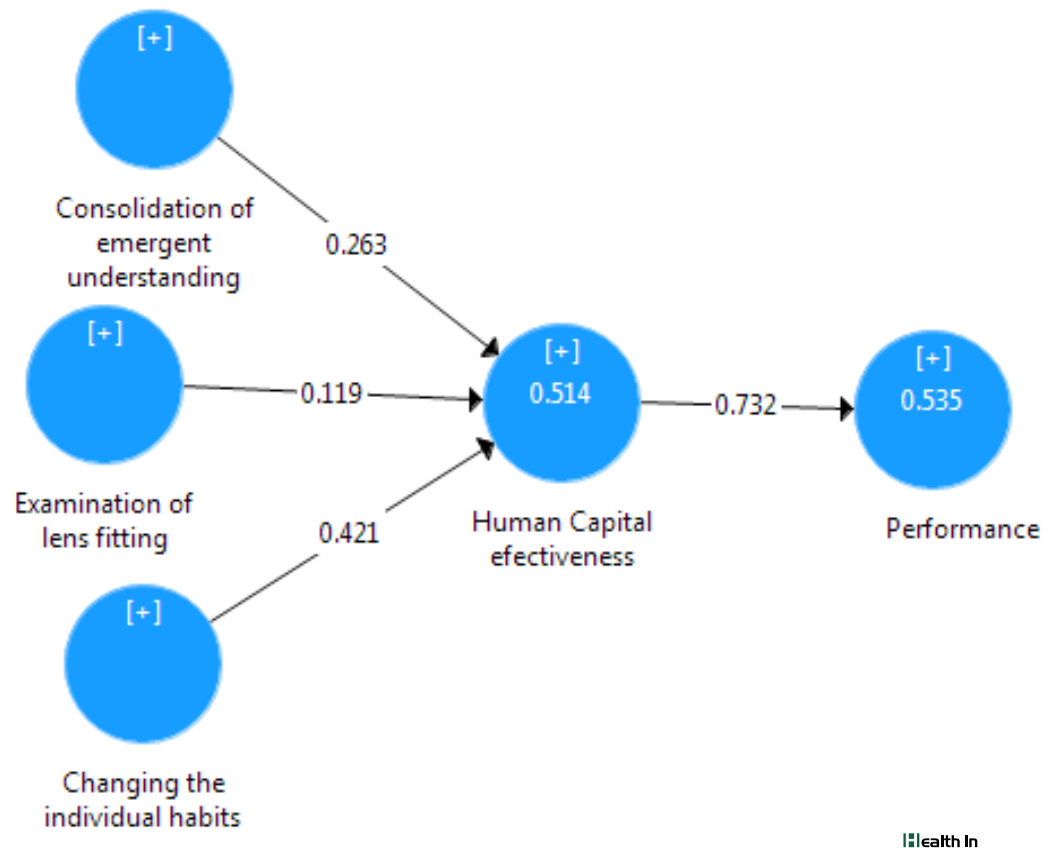

Figure 4. Evaluation of shaping measurement models 
Table 4. Direct effects, t-statistic, and results of research hypotheses

\begin{tabular}{|c|c|c|c|c|}
\hline Hypotheses & $\boldsymbol{\beta}$ & t-Statistic & Sig. & $\begin{array}{l}\text { Rejection or Confirmation of the } \\
\text { Hypothesis }\end{array}$ \\
\hline Integration of concepts emerged $\rightarrow$ Human capital & 0.263 & 2.068 & $P<0.05$ & Confirmed \\
\hline Coordinating insights $\rightarrow$ Human capital & 0.119 & 2.788 & $P<0.05$ & Confirmed \\
\hline Changing individual habits $\rightarrow$ Human capital & 0.421 & 3.339 & $P<0.05$ & Confirmed \\
\hline Human capital $\rightarrow$ Performance & 0.732 & 12.246 & $P<0.05$ & Confirmed \\
\hline
\end{tabular}

As the results of the research, integration of concepts has a positive and significant impact on human capital. Therefore, applying personnel suggestions to new processes, working with managers to solve their problems, and realizing how to respond to unpredicted situations by all members of the organization can lead to improved integration of concepts and ultimately enhance the human capital of the organization.

Considering the findings of the research showing the positive and significant impact of evaluation of the coordinating of insights on human capital, empowering employees and providing them appropriate training to improve their capabilities, such as easy identification of problems (new ways of doing things), ability to deal with colleagues' mistakes, ability of listening to clients (for example complaints, suggestions), ability to share information easily with their boss, and trying to learn from their mistakes can improve and coordinate insights and enhance the human capital of the organization.

\section{Conclusion}

According to the results, changing individual habits can improve the human capital of the organization. Therefore, training employees to improve their skills and change their attitudes, thoughts, and behaviors with the help of new situations is one of the strategies for changing personal habits and enhancing human capital. Our findings indicate a positive relationship between human capital and the performance of emergency bases. They also reinforce the scientific evidence that improvement in human capital development and management may increase organizational performance.

So if emergency bases consider organizational forgetting as an early stage in the creation of human capital, they can improve organizational performance. Besides, the results showed that organizational forgetting has an indirect impact on the performance of emergency bases through the development and extraction of new capabilities and skills that increase the value of human capital (Table 4).

According to the results, it is suggested that emergency bases create a suitable ground for organizational forgetting to get rid of old habits and implement new knowledge among employees by providing them opportunities to attend meetings and conferences, to talk to each other as a team, to participate in projects for carrying out sensitive tasks, and to help them to feel responsibility for collecting internal proposals. Therefore, we managed to provide human capital, and as a result, emergency bases can show better performance.

\section{Ethical Considerations}

\section{Compliance with ethical guidelines}

The plan has been approved by Payame Noor University (Code: 14). Participants were provided with the necessary information about the research purpose and its implementation. Participants were assured of the principle of confidentiality (Code: 25). They were allowed to withdraw from the study at any time and would be provided with the results of the research (Code: 27).

\section{Funding}

The study had no financial backing or sponsorship.

\section{Authors' contributions}

Data analysis: Iman Azizi; Editing and Reviewing: Mirza Hasan Hoseini.

\section{Conflict of interest}

The author declared no Conflict of interest. 


\section{Acknowledgments}

We wish to thank the staff of Shiraz Road Safety and Urban Emergency Medical Workers for their sincere cooperation in this research.

\section{References}

[1] Blaga P, Jozsef B. Human resources, quality circles and innovation. Procedia Economics and Finance. 2014; 15:1458-62. [DOI:10.1016/S2212-5671(14)00611-X]

[2] Paşaoğlu D, Zümrüt Tonus H. Strategic importance of human resource practices on job satisfaction in private hospitals. Procedia - Social and Behavioral Sciences. 2014; 150:394-403. [DOI:10.1016/j.sbspro.2014.09.035]

[3] Izverciana M, Radua A, Ivascua L, Ardeleanb BO. The impact of human resources and total quality management on the enterprise. Procedia - Social and Behavioral Sciences. 2014; 124:27-33. [DOI:10.1016/j.sbspro.2014.02.456]

[4] Kannan G, Aulbur WG. Intellectual capital: Measurement effectiveness. Journal of Intellectual Capital. 2004; 5(3):389413. [DOI:10.1108/14691930410550363]

[5] Becker BE, Huselid MA, Ulrich D. The HR scorecard: Linking people, strategy and performance. Boston, MA: Harvard Business School Press; 2001.

[6] Beygi T, Fotros MH. [The measurement of the effect of human capital on organizational performance in Iranian banking industry: An intangible assets perspective (Persian)]. Journal of Industrial Management. 2010; 4(10):81-9.

[7] Becker K, Hyland P, Acutt B. Considering unlearning in HRD practices: An Australian study. Journal of European Industrial Training. 2006; 30(8):608-21. [DOI:10.1108/03090590610712278]

[8] Becker K. Unlearning as a driver of sustainable change and innovation: Three Australian case studies. International Journal of Technology Management. 2008; 42(1/2):89-106. [DOI:10.1504/IJTM.2008.018062]

[9] Becker K. Facilitating unlearning during implementation of new technology. Journal of Organizational Change Management.2010; 23(3):251-68. [DOI:10.1108/09534811011049590]

[10] Buller PF, McEvoy GM. Strategy, human resource management and performance: Sharpening line of sight. Human Resource Management Review. 2012; 22(1):43-56. [DOI:10.1016/j.hrmr.2011.11.002]

[11] Lopez-Cabrales A, Valle R, Herrero I. The contribution of core employees to organizational capabilities and efficiency. Human Resource Management. 2006; 45(1):81-109. [DOI:10.1002/hrm.20094]

[12] Schottke D. First responder: Your first response in emergency care [R. Shahrami, A. Shahrami, H. Shirzad, M. Naderi Far, Persian trans.]. 4th ed. Tehran; Simindokht; 2009.

[13] Jazayeri AS, Alvani SM. [The study of effects of organizational forgetting on learning and adoption of innovation tech- nology in location general (Persian)]. Journal of Development \& Evolution Management. 2018; 1397(32):1-10.

[14] Poorhatami A, Zarei Matin H, Hayati B, Ataei M. [Investigation the effect of intentional and accidental organizational forgetting on organizational learning process (Case study: Central Office of Jahad Daneshgahi) (Persian)]. Organizational Culture Management. 2016; 13(4):1179-200. [DOI:10.22059/ JOMC.2016.55433]

[15] Sune A, Fernandez V. Organizational forgetting in higher education. Paper presented at: 3rd International Conference on Industrial Engineering and Industrial Management, XIII Organization Engineering Congress. 2-4 September 2009; Barcelona-Terrassa, Spain

[16] Cegarra JG, Wensley A, Sanchez MT. A conceptual framework for unlearning in a homecare setting. Knowledge Management Research and Practice. 2014; 12(4):375-86. [DOI:10.1057/kmrp.2013.6]

[17] Zhao Y, Lu Y, Wang X. Organizational unlearning and organizational relearning: A dynamic process of knowledge management. Journal of Knowledge Management. 2013; 17(6):902-12. [DOI:10.1108/JKM-06-2013-0242]

[18] Wang XY, Lu YQ, Zhao YX, Gong SL, Bai L. Organizational unlearning, organizational flexibility and innovation capability: An empirical study of SMEs in China. International Journal of Technology Management. 2013; 61(2):132-55. [DOI:10.1504/IJTM.2013.052178]

[19] Pew Tan H, Plowman D, Hancock P. Intellectual capital and financial returns of companies. Journal of Intellectual Capital. 2007; 8(1):76-95. [DOI:10.1108/14691930710715079]

[20] Naderi A. [The economics of education (Persian)]. Tehran: Yastoroon; 2015.

[21] Kiker BF. The historical roots of the concept of human capital. Journal of Political Economy. 1966; 74(5):481-99. [DOI:10.1086/259201]

[22] Hitt MA, Bierman L, Shimizu K, Kochhar R. Direct and moderating effects of human capital on strategy and performance in professional service firms: A resource-based perspective. Academy of Management Journal. 2001; 44(1):13-28. [DOI:10.5465/3069334]

[23] Tayles M, Bramley A, Adshead N, Farr J. Dealing with the management of intellectual capital: The potential role of strategic management accounting. Accounting, Auditing \& Accountability Journal. 2002; 15(2):251-67. [DOI:10.1108/09513570210425574]

[24] Ortega J, Cegarra JG, Cepeda G, Leal AL. Linking unlearning with quality of health services through knowledge corridors? Journal of Business Research. 2015; 68(4):815-22. [DOI:10.1016/j.jbusres.2014.11.034]

[25] Wensley AK, Cegarra JG. Overcoming knowledge loss through the utilization of an unlearning context. Journal of Business Research. 2015; 68(7):1563-9. [DOI:10.1016/j.jbusres.2015.01.052]

[26] Cepeda G, Cegarra JG, Martinez E, Eldridge S. How can managers in the hospital in the home units help to balance technology and physician-patient knowledge? International Journal for Quality in Health Care. 2011; 23(5):600-9. [DOI:10.1093/intqhe/mzr046] [PMID] 
[27] Durst S, Runar Edvardsson I. Knowledge management in SMEs: A literature review. Journal of Knowledge Management. 2012; 16(6):879-903. [DOI:10.1108/13673271211276173]

[28] Birasnav M. Knowledge management and organizational performance in the service industry: The role of transformational leadership beyond the effects of transactional leadership. Journal of Business Research. 2014; 67(8):1622-9. [DOI:10.1016/j.jbusres.2013.09.006]

[29] Fornell C. Customer asset management, capital efficiency, and shareholder value: Performance measurement, past, present and future. Paper presented at: Conference in the University of Cambridge. 20 July 2000; Cambridge, England.

[30] Naderi A, Heidari Kebriti T, Amiri A. [Relationship between human capital and organizational performance: The case of Asia insurance company (Persian)]. Research on Educational Leadership and Management. 2016; 2(5):1-30. [DOI:10.22054/JRLAT.2017.11125.1190]

[31] Rezaee F. [Investigation of intellectual capital and its impact on organizational performance of National Iranian Drilling Company (Persian)] [MSc. thesis]. Tehran: Shahid Beheshti University; 2010.

[32] Li S, Ragu-Nathan B, Ragu-Nathan TS, Subba Rao S. The impact of supply chain management practices on competitive advantage and organizational performance. Omega. 2006; 34(2):107-24. [DOI:10.1016/j.omega.2004.08.002]

[33] Marr B, Gary D, Neely A. Why do firms measure their intellectual capital? Journal of Intellectual Capital. 2003; 4(4):44164. [DOI:10.1108/14691930310504509]

[34] Suppiah V, Singh Sandhu M. Organizational culture's influence on tacit knowledge-sharing behaviour. Journal of Knowledge Management. 2011; 15(3):462-77. [DOI:10.1108/1 3673271111137439]

[35] Tsang EWK, Zahra SA. Organizational unlearning? Human Relations. 2008; 61(10):1435-62. [DOI:10.1177/0018726708095710]

[36] Aledo Ruíz MD, Gutiérrez JO, Martínez-Caro E, CegarraNavarro JG. Linking an unlearning context with firm performance through human capital. European Research on Management and Business Economics. 2017; 23(1):16-22. [DOI:10.1016/j.iedeen.2016.07.001]

[37] Liljander V, Polsa P, van Riel A. Modelling consumer responses to an apparel store brand: Store image as a risk reducer. Journal of Retailing and Consumer Services. 2009; 16(4):281-90. [DOI:10.1016/j.jretconser.2009.02.005]

[38] Wixom BH, Watson HJ. An empirical investigation of the factors affecting data warehousing success. MIS Quarterly. 2001; 25(1):17-41. [DOI:10.2307/3250957]

[39] Hair Jr JF, Black WC, Babin BJ, Anderson RE, Tatham RL. Multivariate data analysis ( $7^{\text {th }}$ edition). Edinburgh: Pearson Education; 2010. 
This Page Intentionally Left Blank 